\title{
КУДА «ПРОПАЛИ» ЭМОЦИИ В КОНСТРУКТИВИСТСКОЙ ПСИХОТЕРАПИИ? (НА ПРИМЕРЕ ОРИЕНТИРОВАННОЙ НА РЕШЕНИЕ КРАТКОСРОЧНОЙ ТЕРАПИИ)
}

\author{
Г.Л. БУДИНАЙТЕ
}

\begin{abstract}
${ }^{a}$ Национальный исследовательский университет «Высшая школа экономики», 101000, Россия, Москва, ул. Мясницкая, д. 20
\end{abstract}

\begin{abstract}
Резюме
В ориентированной на решение краткосрочной терапии (ОРКТ), как и в других конструктивистских психотерапевтических подходах, задача направленной работы с эмоциями клиента не ставится. Психотерапевтические техники для реализации такой задачи отсутствуют. В связи с этим время от времени поднимается вопрос о необходимости включить в ориентированную на решение краткосрочную терапию интервенции, направленные непосредственно на эмоции клиента, в дополнение к интервенциям, направленным на мысли и поведение. С нашей точки зрения, дискуссия по этому вопросу не сводится к обсуждению возможного расширения терапевтических техник или инструментов ориентированной на решение краткосрочной терапии, а предполагает анализ собственно методологических оснований этого подхода. В статье рассматриваются теоретические предпосылки классических психотерапевтических направлений, которые с аналитических, структуралистских позиций утверждают необходимость специальной работы с эмоциями клиента как самоценными составляющими психики. Среди рассматриваемых подходов психоанализ, гештальттерапия, гуманистическая психотерапия и эмоционально-фокусированная психотерапия, которую можно отнести к неоклассическим терапевтическим направлениям. Приводится обзор теоретических концепций, сформировавшихся в XX-XXI вв.: философии, психологии, социологии и культурологии, в которых пересматривается традиционный взгляд на эмоции, представленный академической психологией и классической психотерапией. Описывается процесс становления нового постклассического подхода к работе с эмоциями на примере практики когнитивной психотерапии, системной психотерапии и терапевтической работы М. Эриксона. Формулируются основные принципы построения психотерапевтического взаимодействия, основанные на теоретических предпосылках постнеклассической рациональности. Раскрываются их существенные методологические отличия от принципов классической рациональности. Эти предпосылки снимают вопрос о необходимости специальной работы с эмоциями как некими обособленными элементами психики, в силу нерелевантности для конструктивистских подходов, и, собственно, для OPKT.
\end{abstract}

Ключевые слова: конструктивистские направления психотерапии, классические направления психотерапии, ориентированная на решение краткосрочная терапия, эмпатия, онтологизация эмоций, «вторичный конструкт», конструирование предпочитаемой истории, жизненные истории, «решение», трансформация эмоций как трансформация жизненного контекста. 
Конструктивистские или постклассические психотерапевтические подходы в психотерапии направлены на изменение, «пересочинение» жизненных историй людей, на постепенное наращивание «желаемого будущего» в их жизни. Психотерапевтическая работа предполагает построение и воплощение предпочитаемых способов жизнедеятельности, взаимодействия с миром и новых способов описания своей жизненной ситуации (White, Epston, 1990; Фридман, Комбс, 2001; Будинайте, 2005, 2006; Варга, Будинайте, 2005).

В этом психотерапевтическом процессе конструирования и воплощения людьми предпочитаемой жизненной ситуации терапевт не использует приемы, которые направлены собственно на выявление, отражение и анализ эмоций клиента. Конструктивистские подходы вообще не предполагают аналитического исследования предъявляемого клиентом материала, в том числе невербального. Например, в нарративном подходе анализ «проблемы» скорее выдает себя за таковой (Уайт, 2010). Нет в них и техник, направленных непосредственно на освобождение человека от тяжелых эмоциональных состояний или на их преобразование. Это зачастую приводит к утверждениям об «антиэмоциональности» конструктивистских подходов. Как правило, эта критика оказывается обращена к ориентированной на решение краткосрочной терапии (далее - ОРКТ).

Дискуссия о необходимости включения в ОРКТ техник, направленных на эмоции клиента, как дополнительного измерения терапевтической работы возникала с начала 1990-х гг. Эта позиция высказывается и некоторыми адептами подхода, стремящимися восполнить, как им представляется, существующие в нем досадные упущения. Предлагается дополнительно включить в «сфокусированную на поведенческие изменения» ОРКТ недостающую направленность на эмоции.

Так, например, с точки зрения И. Липчик, Х. Кисер и У. Пайерси, теория и практика ОРКТ может быть усовершенствована за счет изучения и расширения места эмоций в этом подходе (Kiser et al., 1993; Piercy et al., 2000)².

\footnotetext{
${ }^{1}$ Такая работа часто выполняется людьми стихийно, являя собой тем не менее пример целостной трансформации ими самими обыденной жизненной ситуации:

«Ужасно себя чувствую, когда меня обгоняют, тем более подрезают на дороге. Меня прямо захватывает злость, я тут же начинаю толкаться. Иногда так дотолкаться можно, что зеркало сорвать себе... Но вот вчера, знаете, один втискиваться начал, и я его... пропустил, ну вот как-то взял и пропустил, даже не знаю, как вышло. А он мне раз - включил аварийку, значит, в благодарность. И я чувствую, не раздражает он меня, а ведь я прямо до этого уже кипел: “Ну куда лезешь?”. И дело не в его аварийке - успокоился я как-то, чувствовал себя иначе, смотрю - нормальный человек какой-то, сам я потом дистанцию держал и еще мог кого пропустить - вроде как не так важно стало... Ну потом, правда, там пробка была, гаишник регулировал, и тут опять..» (из рассказа клиента).

${ }^{2}$ Авторы подчеркивают, что эмоциональное развитие начинается в жизни человека очень рано, а эмоции, наряду с когнициями и поведением, формируют сложные последовательности событий, включающие взаимодействие с другими, которые со временем закрепляются в каче-
} 
Вопрос о «внеэмоциональности» ОРКТ время от времени возникает и в терапевтических дискуссиях отечественных специалистов по психотерапии, в том числе практикующих в ОРКТ ${ }^{3}$.

С нашей точки зрения, дискуссия по этому вопросу не сводится к обсуждению возможности или невозможности обогащения технического репертуара подхода. Представляется, что он затрагивает собственно методологические основания и принципы терапевтической теории, на которые опирается ОРКТ.

\section{Принципы работы с эмоциями в классических психотерапевтических направлениях}

В классической психологии и психотерапии ${ }^{4}$ исходной является аналитическая, или структуралистская, позиция как исследователя, так и психотерапевта. Зачастую явно или неявно это проявляется в том, что:

1) эмоции, переживания являются неотъемлемыми составляющими «внутреннего» мира человека. Они во многих концепциях понимаются как универсальные, присущие человеку изначально реакции на определенные воздействия, способы переживания тех или иных жизненных обстоятельств. В любом случае эмоциональные переживания выступают как некий опыт взаимодействия

стве устойчивых, гомеостатических паттернов. И. Липчик, Х. Кисер и У. Пайерси отмечают, что, так как эмоции, когниции и поведение взаимосвязаны, то эмоции могут оказывать влияние на когнитивные процессы, и предлагают сосредоточиться на том, как лучше использовать аффективные проявления клиента в процессе изменений. Авторы полагают, что присоединение к негативным эмоциям клиента может иногда способствовать созданию контекста для осуществления им изменений и конструктивных действий. Кроме того, с их точки зрения, обсуждение эмоций клиента играет значительную роль в создании терапевтического климата совместности, а также может расширить классические техники ориентированной на решение краткосрочной терапии: вопрос о чуде, вопросы об исключениях, шкалирование и др. Более подробное описание практических приемов, направленных на работу с эмоциями в ОРКТ, представлено в книге Ив Липчик (Lipchik, 2002).

${ }^{3}$ Так, на первой онлайн-конференции в России, организованной профессиональным сообществом ОРКТ в России весной 2016 г., поднимался этот вопрос. Текст выступления Г.Л. Будинайте на первой очной конференции по ОРКТ в ноябре 2016 г. лег в основу этой статьи (с материалами конференции можно ознакомиться на сайте http://2016.sfbt-conference.ru).

${ }^{4}$ Границы ее условны, как и любые границы различных этапов развития мысли. Очевидно, что само терапевтическое мышление является неклассическим по отношению к так называемой классической научной рациональности (см.: Степин, 2009), хотя и осознается это в самой психотерапии не сразу.

Тем не менее постклассическими в самой психотерапии уже принято считать подходы, основывающиеся на так называемых постмодернистских, постструктруктуралистических и конструктивистских идеях, в то время как многие подходы, возникшие вслед за этими последними (преимущественно в начале 2000-х гг.), но вновь опирающиеся на аналитические структуралистские позиции, можно определить как неоклассические. 
человека с миром, подлежащий специальному анализу как условие разрешения его проблем;

2) переживаемые одним человеком состояния могут быть доступны другому. Человек может пониматься при этом как некая независимая, сформировавшаяся к моменту взаимодействия сущность. А его состояния и переживания могут быть доступны психотерапевту благодаря эмпатии, вчувствованию или использованию каких-то специальных профессиональных манипуляций, например, экспертного анализа. Так, многие авторы рассматривают эмпатическое слушание в качестве основополагающего, базового навыка терапевта, как необходимый неспецифический фактор продуктивного терапевтического контакта и эффективного решения основных психотерапевтических задач (см.: Elliott et al., 2011; Mommaerts et al., 2012; Wampold, 2015).

Такое понимание терапевтических задач в существенной степени конструировало и во многом продолжает конструировать не только собственно профессиональное, но и социальное пространство психотерапии. Ему соответствует определенный формат, дизайн терапевтического взаимодействия".

В то же время терапевтические задачи и логика работы с эмоционально насыщенным «материалом» клиента в каждом из психотерапевтических подходов, которые можно отнести к классическим, специфичны.

В психоанализе аффективно окрашенный материал выступает для психоаналитика маркером бессознательного. М. Шерман, детально анализируя работы 3. Фрейда, отмечает, что аффект или эмоции рассматривались Фрейдом как производные от бессознательных инстинктов и часто обсуждались в контексте психической энергии, которая может разрядиться или создать напряжение. С точки зрения 3. Фрейда, вытесняемые аффективные переживания могли переноситься на другие объекты или конвертироваться в соматические симптомы. В силу этого необходимо непосредственно иметь дело с аффективно окрашенным психическим материалом для того, чтобы, исследовав содержания психики, вернуть человеку власть над своими аффектами (Sherman, 1983).

Таким образом, в психоанализе, с одной стороны, намечена возможность рассмотрения эмоций как натуральных сущностей, связанных с некими внутренними базовыми бессознательными инстинктами. В то же время значение аффекта для психоаналитика состоит в «маркировке» других психических содержаний. Тем самым обозначается инструментальная функция эмоций. В дальнейшем в развитии техник работы с эмоциями в психотерапии можно увидеть обе эти линии.

\footnotetext{
${ }^{5}$ Дж Хейли в своей знаменитой и, надо признать, почти фельетонной работе «The art of psychoanalysis» (Haley, 2007), ссылается на главный, по его мнению, психоаналитический «мем»: «Но вопрос в том, то ли это, что вы чувствуете на самом деле?» («I wonder if that really what you are feeling?»). Этим подчеркивается ключевая идея действительного, «подлинного» знания, необходимость установления которого как исходная и фундаментальная задача предъявляется клиенту. Она повергает клиента в смятение, потому что в его восприятии этим действительным знанием располагает только психоаналитик как эксперт «по чувствам».
} 
Своеобразный натурализм в подходе к эмоциям представлен и в классической гештальттерапии, где статус базовой придается пищевой потребности. Метафорой всех «встреч» организма-индивида и окружающей среды-фона становится метафора поглощения (Перлз, 2001). Фон потенциально содержит объекты для удовлетворения более или менее фиксированного набора потребностей, которые в момент встречи-контакта образуют «фигуру». И успешная встреча, и прерывание или застревание контакта связаны с разнообразными эмоциями. Эмоции - постоянный «тон» разнообразных взаимодействий индивида со средой. Таким образом, в гештальттерапии можно увидеть как продолжение натуралистической линии, так и идеи инструментального значения эмоций. Они выступают как сигналы и знаки, позволяющие считывающему телесные и эмоциональные проявления клиента терапевту проводить терапевтический эксперимент по проработке существующей проблемы. Эмоции, наряду с другими «измерениями», могут открыть доступ к осуществлению «творческих контактов» в «здесь и теперь» терапевтического процесса, обеспечивающего в первую очередь не собственно разрешение проблемы или избавление от невроза, а личностный рост (Хломов, 2000). В гештальтподходе делается важный шаг к констатации целостности опыта пациента, но он видится скорее как совокупность разных «измерений» опыта, выделяемых со структуралистских позиций.

Представляется, что особый интерес к эмоциям в терапевтическом процессе как к неким натуральным и в то же время индивидуальным и сущностным состояниям человека связан с вышедшим на авансцену в середине XX в. гуманистическим подходом. В логике этого подхода природа человека - в противоположность распространившейся психоаналитической интерпретации человеческой природы как якобы «негативной» - должна была быть утверждена как «позитивная». При этом сохраняется психоаналитическая идея репрессивности социального и культурного по отношению к натуральному. Тогда возможность выражения не искаженных давлением социума, его условностями и искусственностью, устремлений, связанных с ними эмоциональных переживаний человека, должна обеспечиваться свободным эмпатическим, конгруэнтным, принимающим контактом клиента с психотерапевтом (см.: Карягина, 2016). В гуманистической парадигме эмпатическое сопереживание терапевта нацелено на развитие у клиента доверия к его собственным внутренним переживаниям, на преодоление отвержения им самим своих натуральных, но социально не одобряемых устремлений, достижение самопринятия и внутреннюю реорганизацию его Я-концепции (Роджерс, 1994; Роджерс и др., 2001). Заметим, однако, что, несмотря на эту постулируемую связь эмоций с позитивной природой человека, конкретная содержательная направленность эмоциям здесь все же не приписывается. Психотерапевт принципиально открыт содержаниям, только раскрывающимся в непосредственном контакте с клиентом (Роджерс, 1994). 
Можно сказать, что именно со становлением гуманистического подхода в психотерапии утверждается еще и особая ценность эмоцийб.

Однако своеобразным следствием этого становится линия на онтологизацию эмоций, реализующаяся в некоторых современных терапевтических направлениях. Так, одним из наиболее ярких выражений этой аналитической структуралистской линии является сегодня эмощионально-фокусированная терапия (Greenberg, Johnson, 1988; Johnson, 2012; Микаэлян, 2011; Черников, 2011). Эмоционально-фокусированный терапевт исходит из того, что существует набор универсальных, базовых эмоций, которые составляют основу любых эмоциональный реакций. В психотерапии он занимает позицию эксперта по эмоциям, который учит клиента распознавать, с какой именно эмоцией он имеет дело, и полноценно проявлять их.

\section{Становление постклассического подхода к эмоциям в терапии}

С точки зрения постклассической методологии перечисленные выше принципы основаны на допущениях, характерных для структуралистского подхода. Оперирование понятием эмоций в классических и неоклассических направлениях психотерапии как бы неявно предполагает, что теоретический статус этого понятия очевиден и универсален. Однако и в академической психологии до сегодняшнего дня это не так: очевидно, наблюдается большая пестрота и разнообразие теоретических классификаций (Вилюнас, 1984; Cabanac, 2002; Widen, Russell, 2010).

Но, главное, использование понятия, стремящегося на теоретическом уровне обобщить разные классы феноменов, подразумевает в классических и неоклассических терапевтических подходах возможность «обратного» движения, а именно буквальное уравнивание теоретического понятия с онтологической реальностью. Некоторые авторы полагают в этой связи, что можно говорить об оперировании в терапевтических теориях «вторичными конструктами» эмоций. Согласно М. Шульцу, первичные конструкты - это обобщения и представления, бытующие в обыденном сознании, тогда как вторичные - это онтологизация этих представлений в научном мышлении (см.: Miller, de Shazer, 2000).

Таким образом, представление об эмоциях в терапевтической теории и связанные с ними терапевтические задачи для конструктивиста - не что иное, как результат сначала абстрагирования, выделения в качестве теоретических

\footnotetext{
${ }^{6}$ Эти идеи представляли собой еще и социально значимый манифест гуманистических ценностей: бережного отношения к человеку и его «природе», к его постулируемым сущностным устремлениям и т.п. Этому есть объяснение. Прежде всего, необходимо иметь в виду фоновые социальные процессы - восстановление после тяжелейшей травмы чрезвычайных по трагическим последствиям Первой и Второй мировых войн, либерализация 1960-х гг., антипсихиатрическое движение и т.д. Это особенно заметно по тому, как поддерживается идея ценности эмоций и, напротив, порицается предполагаемая вне- или антиэмоциональность в период выхода гуманистического подхода на авансцену.
} 
бытующих в обыденном сознании представлений, а затем оперирование ими как некой доступной онтологической реальностью и приписывание этих «внутренних содержаний» людям.

По мнению С. де Шейзера, таким путем возникает целая отрасль профессионально направленных на изучение и работу с эмоциями специалистов (см. их классификацию: Ibid.). Эти специалисты постулируют «центральное место эмоций в жизни людей», развивают «эволюционное учение об эмоциях», представление о «базовых эмоциях» и берут на себя задачи их распознавания и профессиональной интерпретации.

Однако с конструктивистских позиций к этой постулируемой реальности эмоций у нас нет никакого прямого доступа. Возникновение, тем более транслирование того, что мы определяем как содержание эмоционального переживания, неотделимо от социального конструирующего контекста взаимодействия человека с миром, включая, конечно, и ситуацию терапевтического взаимодействия ${ }^{7}$ В этом смысле все утверждения о «присущих самой природе человека базовых эмоциях» как минимум не могут быть эмпирически проверены.

Кроме того, в конструктивистской логике человек - сложная не только и не столько проявляющаяся или даже саморегулирующаяся, сколько развивающаяся во взаимодействии с миром живая система. Взаимодействие с человеком вообще не может предполагать аналитическую задачу отражения и постижения некоего заранее утверждаемого «внутреннего» содержания. Оно, напротив, предполагает построение исследования или взаимодействия с этой живой системой с исходной ориентацией на ее еще только возможное развитие. Очевидно, в наибольшей степени это справедливо для терапевтического взаимодействия как прямо направленного на достижение необходимых клиенту изменений.

Ретроспективно линия «антионтологизирующего», инструментального подхода к эмоциональным состояниям выявляется еще в ряде классических терапевтических подходов.

${ }^{7}$ Г. Миллер и С. де Шейзер ссылаются на мысленный эксперимент, который предложил провести философ Л. Витгенштейн. Пусть в случае переживания специального, ранее никогда не переживавшегося состояния некто Стив помечает его в своих записях буквой «С» и делает так каждый раз, переживая его. Представим, что он захотел бы поделиться пережитым, показывая кому-то исписанные буквой «С» листочки. Однако, очевидно, для собеседника Стива тут неизбежен целый ряд трудностей:«Как бы мы могли узнать, что Стив переживает именно это состояние "C”, находясь в нашем присутствии? Как мы могли бы узнать, что тоже переживали “C”? Возможно ли, что мы уже переживали “C”, но перепутали его с чем-то другим? Может ли быть так, что у нас есть переживание, которые вы полагаете таким же, как “С”, но ошибаетесь?» Все другие варианты установления здесь ясности - детальное описание Стивом, что же он чувствует, наша попытка понять это по косвенным признакам (прежде всего, конечно, невербальным) не продвигают нас существенно от ситуации с попыткой обозначения переживания буквой «С». Нам не уйти от интерпретации в том смысле, что нам, строго говоря, никогда не может быть доступен опыт Стива, как он есть сам по себе (Miller, de Shazer, 2000, p. 9). 
Так, в когнитивной психотерапии мишенью терапевтического воздействия в работе с субъективно трудными для пациента эмоциональными переживаниями, например фобиями, являются, в первую очередь, не его переживания «сами по себе», а мысли и лежащие в их основе базовые убеждения и обуславливающие, собственно, эти переживания. Таким образом, изменение способа мышления и описания оказывается необходимым условием для терапевтического изменения того, что рассматривается как эмоциональные реакции человека на те или иные события и ситуации его жизни (см., например: Shean, 2003).

Логика действенного, антианалитического преобразования эмоционально трудной ситуации клиента особенно заметна в разнообразных не только эффектных, но, главное, эффективных терапевтических кейсах М. Эриксона. Состояние клиента не выявляется, не анализируется, не интерпретируется. Изменение обеспечивается трансформацией смыслового, жизненного контекста. Эриксон мог заставить клиента иначе себя чувствовать, действуя и думая иначе (Хейли, Эриксон, 2001; Эриксон, 1995).

Системный подход в психотерапии был первым последовательно переформулировавшим классические терапевтические задачи условно неклассическим подходом. Благодаря переносу акцента с индивидуальной психики на систему коммуникации и взаимодействия, в которую включен носитель симптома, переживание или состояние клиента не рассматривалось больше «само по себе» и не понималось как некая онтологическая реальность. Путь к изменению состояния лежит в изменении не «его самого» - о нем ничего определенно утверждать нельзя, - а системы взаимоотношений, в которых оно возникает. Предъявляемая эмоция рассматривается как послание или сообщение в системе коммуникации, поскольку ее носитель уже включен во взаимодействие и бесполезно задаваться вопросом, каков он или что он чувствует вне или до этого взаимодействияв.

Для системного терапевта именно правила взаимоотношений в системе задают «норму чувствования» ее членов, а эмоциональные проявления членов семьи рассматриваются как часть процесса семейной коммуникации (см., например: Сельвини Палаццоли и др., 2002).

Любопытный пример эволюции подхода к работе с эмоциями в психотерапии представляет собой и постмодернистский вариант гештальттерапии (Уилер, 2005). Стремление преодолеть индивидуалистскую онтологию мира, на которую опирался классический гештальтподход, приводит к рассмотрению процесса решения проблемы с целостно-полевой, процессуальной точки зрения9.

\footnotetext{
${ }^{8}$ Так, согласно этой логике, если супружеские отношения разворачиваются как борьба и соперничество супругов друг с другом, то предъявляемые ими друг другу эмоции невозможно разъять с самим этим характером процесса взаимодействия. Иногда этот коммуникационный и при этом заданный правилами их взаимодействия (например, соперничества) аспект чувствования становится очевиден самим клиентам. Так, одна клиентка говорит: «Я стала опять веселой - и он не мог понять, как это после того, что он сделал и так меня расстроил, может быть. Спать злой ушел».

${ }^{9}$ Self теперь выступает «как активность, которая предстает в контакте». Решение проблемы человека не является больше результатом исследования и трансформации опыта «Я», вступаю-
} 
Продолжением этой линии уже на новом витке развития теоретической мысли выступили конструктивистские терапевтические подходы.

\section{Неклассическая психология, неклассическая гуманитарная мысль и проблема эмоций}

Конструктивистский подход к проблеме эмоций в психотерапии стоит рассматривать в более широком контексте развития гуманитарной мысли XX и XXI вв., обращавшейся к этой проблеме.

Эмоции в культурно-исторической психологической конщепщии Л.С. Выготского. Невозможность подходить к аффективным образованиям человека как сугубо натуральным явлениям была, как известно, важнейшей посылкой культурно-исторической концепции Л.С. Выготского. Здесь особенно важны две идеи Л.С. Выготского. Первая - невозможность рассматривать эмоции как особую, отделенную от остальной психической жизни человека реальность: единство аффекта и интеллекта, встроенность эмоциональных процессов во все другие психические процессы (см.: Выготский, 1982б; Чеснокова, 1999).

Другая - идея развития эмоциональной сферы в социальной и культурной деятельности, в которую исходно включен человек, поскольку, согласно Выготскому, мы всегда имеем дело с ситуацией, в которой «натуральный» человек - не более чем абстракция. С ней связана другая фундаментальная идея: аффективно-смысловые образования человека изначально существуют в культурно-историческом пространстве, а лишь затем усваиваются человеком и существуют в интрапсихической форме.

Отсюда один шаг до утверждения неустранимости культурного социального контекста в любом наблюдаемом проявлении человека, когда идея трансляции, выражения в языке, в ритуале или культурной форме некоторого натурального эмоционального состояния человека сменяется идеей, формирующей, производящей и ориентирующей роли этих средств в преобразовании в человеке этого натурального.

щего в разнообразные контакты с противопоставленным ему миром. Они черпаются из контекста, ресурсов поля как прежде всего социальной среды, в которой действовал в прошлом и теперь живет человек. При этом эмоции продолжают выступать терапевтическим инструментом как осознания человеком субъективной значимости проблемы, ограниченности прежних средств, имевшихся у него для решения существующей сложности, так и удачного опыта нахождения решения.

Представляется, что за развитием идеи «контакта» как целостности процессов всех уровней, включающих в себя и эмоциональный, продолжает, тем не менее, сохраняться собственно структуралистская логика дифференциации психических процессов. Сохраняется и классическая идея исследования проблемного опыта как этапа, неизбежно предшествующего разрешению проблемы. Однако при этом в подходе Г. Уилера подчеркивается, что изменение - целостный процесс, а трансформация тяжелых переживаний осуществляется через преобразование социальной коммуникации и поведения человека, а не путем исключительно аналитического исследования и воздействия на трудные эмоциональные состояния. 
Теория языковых игр Л. Витгенштейна. Философские труды Л. Витгенштейна оказали значительное влияние на развитие конструктивистского представления о невозможности рассмотрения и анализа эмоций человека вне учета контекста социального взаимодействия. Именно на ключевую идею Витгенштейна о невозможность прямой и универсальной экспликации субъективного опыта с помощью языка опирается в своих уже упомянутых выше работах Стив де Шейзер (Miller, de Shazer, 2000). В текстах философа развивается мысль о том, что слова языка, используемые для обозначения постулируемых внутренних психических процессов, не имеют общедоступного предмета референции. Поэтому эти слова не имеют и устойчивых, универсальных значений: интерпретация значения слова определяется контекстом, в котором оно используется, и языковыми играми, т.е. коммуникативными практиками, в которых слова приобретают определенное значение. То, как люди используют язык и какие социальные реальности тем самым создаются, определяется конкретными и практическими обстоятельствами социального контекста. Например, одно и то же слово приобретает разные значения во фразах «Боюсь, что не смогу вам помочь» и «Я боюсь собак». Жизнь состоит из последовательности эпизодов языковых игр, которые формируют формъь жизни (цит. по: Harré, 2009).

Теория коммуникации. Согласно теории коммуникации (Вацлавик и др., 2000 ), выражение эмоций в ходе общения (например, радости или агрессии) необходимо рассматривать как сообщение о том, как участник взаимодействия воспринимает собеседника и свои отношения с ним, а не только и не столько как информацию об его эмоциональном состоянии «самом по себе». В теории коммуникации была сформулирована фундаментальная идея о том, что сама система коммуникации и ее особенности необратимо определяют транслируемые участниками коммуникационного процесса друг другу состояния. Вклад условно исходных состояний участников коммуникации в этот процесс уже неопределим, а сама постановка такого вопроса не имеет терапевтического смысла (это представление является ключевым для системной семейной психотерапии).

Переживание эмоций как активность, предписанная в рамках сочиальной роли. В рамках развивающегося со второй половины XX в. направления «социология эмоций» формулируется идея рассмотрения эмоциональных проявлений в контексте выполнения человеком определенной социальной роли и, в частности, социально сконструированных «эмоциональных правил», в известном смысле «предписывающих» переживание определенных эмоций в различных ситуациях (Деева, 2010; Fox, 2015; Frijda, Mesquita, 1994; Goffman, 1973). Ярким примером «эмоциональных правил» является «обязательность» определенных эмоциональных проявлений на похоронах или праздничном мероприятии. Влияние принятых «стандартов» переживания эмоций в рамках тех или иных социальных ролей регулярно обнаруживается в клинической практике в ситуациях, когда клиенты говорят, например, о чувстве вины, связанном с их неспособностью испытывать «полагающиеся» им как родителям, супругам или детям чувства, и т.п. 
Концепция эмоций в современной культурологии. Согласно культурологической концепции (Зорин, 2006), эмоции человека никогда не являются уникальными, так как при переживании эмоций мы опираемся на символические образцы, представленные в религии, произведениях искусства и средствах массовой информации. Эти символические модели переживания не однородны, находятся в отношениях напряжения, несовпадения и конфликтов и складываются в уникальную, неповторимую констелляцию индивидуального переживания.

В соответствии с сочиально-конструктивистским подходом к әмоциям, эмоции рассматриваются как социальные конструкты (см.: Кутковой, Стефаненко, 2014; Harré, 2009). Основным предметом изучения являются языковые конструкции, включающие эмоциональные слова и выражения. Так, в теории, разработанной Р. Харре, подчеркивается неотделимость предъявляемых эмоций от социальных эпизодов и ситуаций, в которых они проявляются. Эмоция рассматривается как комплексное образование, включающее физиологическую реакцию, которая возникает в зависимости от способа интерпретации человеком значения ситуации, и определенные поведенческие формы реагирования, рассматриваемые как социальные акты выражения позиции человека по отношению к происходящему. В то же время Р. Харре обращал внимание на наличие сложной взаимосвязи между способом интерпретации ситуации и локальными убеждениями, этическими правилами и социальными конвенциями. Это обуславливает культурную специфичность эмоций, уникальность «эмоционального репертуара», характерного для разных культур (Harré, 2009).

В теории эмоций Лизљ Фельдман Баретт статус эмоций как «онтологически объективных» также ставится под сомнение. Баретт детально анализирует существующие эмпирические данные о нейрофизиологических процессах, связанных с переживанием эмоций, и показывает необоснованность распространенного представления об эмоциях как универсальных, сформировавшихся в ходе эволюции реакциях. Ссылаясь на работы философа Джона Сирла, она определяет статус эмоций как скорее «онтологически субъективной реальности» и подчеркивает, что переживание эмоций тоже является частью процесса социального конструирования (включающего категоризацию окружающего мира, его языковое осмысление и когнитивные умозаключения) (Barrett, 2012).

Наконец, в отечественной психологии сформировалось и продолжает развиваться чрезвычайно важное для терапевтических конструктивистских подходов методологическое положение о психотехнической природе исследования человека (Выготский, 1982а), как и всякого взаимодействия с человеком в целом (Мамардашвили, 1992; Пузырей, 1986; Василюк, 1988, 2007; Стеценко, 1990; Stetsenko, 2016). Взаимодействие с человеком как изменяющейся живой системой в этом понимании должно оставлять место для изменения и необратимого преобразования постулируемых «исходных» состояний и переживаний в самом этом процессе взаимодействия, а значит, исходно ориентироваться на это еще «только возможное». 
Таким образом, с середины XX в. в психологии и других гуманитарных дисциплинах развивается и все больше утверждается представление о неотъемлемости эмоциональных процессов человека от культурных и социальных конструктов и культурных средств, которыми оперирует человек для осознания, выражения и предъявления своих состояний.

Утверждается невозможность прямой экспликации внутреннего, субъективного опыта, более того, бессмысленность такой постановки задачи во взаимодействии с живыми развивающимися системами.

\section{Конструктивистский подход в терапии}

Ориентация конструктивистских направлений психотерапии на представленные выше теоретические положения обуславливает перенос фокуса терапии с отражения, исследования и реконструкции предполагаемых эмоциональных состояний «как они есть» на создание условий для возникновения целостных жизненных историй взаимодействия людей с миром, включающих в себя, в частности, и желаемые для людей эмоциональные состояния и переживания.

Эмоциональные состояния, что бы под этим ни имелось в виду, конечно, не игнорируются, если клиент их предъявляет и хочет о них говорить. Однако конструктивистские подходы фокусируются и в этом случае на контексте, в котором проявляются те или иные «трудные эмоции»: на жизненных ситуациях и совершаемых в них действиях, а затем - на помощи клиентам в конструировании жизненных ситуаций, в которых они чувствовали себя лучше в прошлом или смогут почувствовать себя лучше (Miller, de Shazer, 2000). На первый план выступает не анализ негативных эмоций и задача избавления от них, а создание условий, контекстов, порождающих, помимо всего остального, и эти позитивные в восприятии конкретного человека эмоциональные состояния ${ }^{10}$.

Суммируя вышесказанное о конструктивистских подходах, можно заключить:

1. Терапевтические задачи, связанные, в частности, с преодолением трудных состояний клиентов, всегда включены в более широкий контекст достижения желаемого изменения в актуальной жизненной ситуации клиентов.

\footnotetext{
${ }^{10}$ Любопытно, что академические концепции, в том числе эволюционные, сегодня обосновывают возможность изменения эмоций через изменение контекста и ориентацию на положительные, а не негативные эмоции. Так, согласно биоинформационной теории П. Ленга, изменение эмоциональных реакций на ту или иную ситуацию возникает в результате изменения ассоциативной цепочки, лежащей в основе этой реакции. Таким образом, изменение поведения - это самый простой способ трансформации эмоциональных реакций (см.: Bannink, 2007). С точки зрения создателя теории об эволюционной функции положительных эмоций Б. Фридрексон, позитивные эмоции расширяют поведенческий репертуар человека, усиливают его резистентность, креативность и таким образом способствуют более гибкому функционированию человека (см.: Kim, Franklin, 2015).
} 
Технически это воплощается в том, что, как пишет С. де Шейзер, в действительности предлагаемая работа «непосредственно с эмоциями» неизбежно приведет к вопросам о действиях, жизненных активностях, взаимодействиях с другими людьми, общении человека и т.П., которые сопровождают всякое более приятное желательное эмоциональное состояние или уже приводили к нему (см.: Miller, de Shazer, 2000) ${ }^{11}$.

Возникновение прямого запроса на преодоление трудных состояний или даже на «работу с эмоциями» является частным случаем и способом клиента «маркировать» для себя самого цели терапии. Это уважается, но никак не меняет принципиально логику терапевтической работы. Логика терапевтического взаимодействия с клиентами и с возникающими в нем терапевтическими текстами определяется задачей необходимого клиенту развития. В силу этого обсуждается не то, что есть «на самом деле», а предпочитаемая клиентами жизненная ситуация, жизненная история и, если необходимо, соответствующие ей эмоциональные состояния и переживания.

2. В каждом из конструктивистских подходов очевидно стремление формировать определенный этический характер терапевтических взаимоотношений. А именно отказ от экспертной терапевтической позиции и учет «производящей», формирующей функции самого терапевтического взаимодействия приводят к стремлению обеспечить сотрудничающее взаимодействие с клиентом. Тем самым накладывается ограничение на стремление с экспертных позиций эксплицировать внутренний опыт клиента. Оно связано с пониманием неизбежного влияния «исследователя на объект исследования», влияния собственного опыта и позиции психотерапевта в таком экспертном взаимодействии, а также с необходимостью не просто учета, но последовательного инициирования собственной активности клиента в построении нужного ему жизненного текста (см.: Будинайте, 2005; Будинайте, Геронимус, 2016).

3. Этот подход реализуется сегодня в терапевтической работе с теми запросами, где традиционно одной из важнейших терапевтических задач является помощь клиенту в «проживании» своих чувств. Речь идет о работе с горем как помощи в воссоздании жизненного нарратива после переживания утраты (см.: Neimeyer, 2010). Конструктивистский подход к работе с психологической травмой фокусируется на способности клиента выстроить предпочитаемый жизненный нарратив вопреки травмирующему событию (см.: Merscham, 2000 ), а кризисные интервенции направлены на актуализацию ресурсов клиента (Greene, Lee, 2015). Эта логика работы с травмой очень близка к работе с

\footnotetext{
${ }^{11}$ Примечательно, что если посмотреть с конструктивистских позиций на логику трансформации сложных эмоций и переживаний как осуществляющуюся не прямо, а инструментально, через изменение не самих состояний напрямую, а через изменение поведения, то именно это «действенное» изменение своего состояния производит ребенок в классическом тексте 3. Фрейда. Малыш, переживающий уход матери, бросает катушку и демонстрирует видимое удовольствие от возвращения (обретения) этого предмета вновь (он тянет ее назад на ниточке). проделывая это опять и опять (Фрейд, 1992, с. 208). Это впечатляющее обретение власти над трудным состоянием. Эта же трансформация заметна и в приведенном в эпиграфе из монолога клиента.
} 
использованием ресурсов, находимых самим клиентом в его жизненной истории, и перевоссозданием его целостной жизненной линии в ОРКТ.

В последнее время публикуются и эмпирические данные об эффективности применения идей ОРКТ в работе с тяжелыми эмоциональными состояниями ${ }^{12}$.

Итак, мы ставили перед собой задачу показать, что представление о необходимости специальной терапевтической работы с эмоциями клиента вытекает из специфического преломления классической научной методологии и натуралистического подхода к эмоциям в классических и неоклассических терапевтических подходах. Нельзя не согласиться со Стивом де Шейзером в том, что ОРКТ «рассказывает совсем другую терапевтическую историю» (Miller, de Shazer, 2000). Эта терапевтическая история вырастает из иной философии и методологии построения терапевтического взаимодействия и иного подхода к достижению терапевтических изменений.

\section{Литература}

Будинайте, Г. Л. (2005). Ориентированная на решение краткосрочная терапия. В кн. А. В. Черников (ред.), Системная семейная психотерапия: классика и современность (с. 233-270). М.: Класс.

Будинайте, Г. Л. (2006). Особенности обучения постклассическому методу психологической помощи семъе: в системе «Ориентированной на решение краткосрочной терапии» [Кандидатская диссертация, Институт развития дошкольного образования, Москва].

Будинайте, Г. Л., Геронимус, И. А. (2016). Использование в работе на телефоне доверия подхода «Ориентированная на решение краткосрочная психотерапия»: учебно-методическое пособие. М.: ГБОУ ВПО МГППУ.

\footnotetext{
${ }^{12}$ Так, например было проведено сравнительное исследование эффективности классической когнитивно-бихевиоральной терапии и метода позитивной когнитивно-бихевиоральной терапии при лечении депрессии. Метод позитивной конгитивно-бихевиоральной терапии был разработан авторами статьи. Он предполагает модификацию техник когнитивно-бихевиоральной терапии с опорой на идеи ориентированного на решение подхода (отношение к клиенту как к эксперту в своей жизни, фокус на предпочитаемом клиентом будущем и исключениях из проблемы и т.д.), а также использование некоторых упражнений из позитивной психологии. Результаты исследования показывают, что на протяжении первого этапа лечения улучшение депрессивных симптомов происходило одинаково, независимо от используемого метода. В то же время на втором этапе лечения улучшение эмоционального состояния у пациентов, проходивших позитивную когнитивно-бихевиоральную терапию, было значительно выше (Geschwind et al., 2019). Кроме того, проведен ряд исследований, доказывающих эффективность ОРКТ в групповой терапии при работе с депрессией (Javanmiri et al., 2013; Maqami et al., 2016). Существуют публикации о работе с посттравматическим стрессовыми расстройством в ОРКТ (Gonzalez, 2017; Dolan, 1994), а также о применении ОРКТ для помощи семьям с неизлечимо больным членом семьи (Simon, 2009). В этих публикациях нет данных о результатах исследования эффективности терапии, однако приводятся примеры успешных кейсов работы с этими запросами.
} 
Варга, А. Я., Будинайте, Г. Л. (2005). Теоретические основы системной семейной психотерапии. В кн. А. В. Черников (ред.), Системная семейная психотерапия: классика и современность (с. 11-60). М.: Класс.

Василюк, Ф. Е. (1988). Уровни построения переживания и методы психологической помощи. Вопросы психологии, 5, 27-37.

Василюк, Ф. Е. (2007). Семиотика и техника эмпатии. Вопросы психологии, 2, 3-14.

Вацлавик, П., Бивин, Д., Джексон, Д. (2000). Прагматика человеческих коммуникаций: Изучение паттернов, патологий и парадоксов взаимодействия. М.: Апрель-пресс.

Вилюнас, В. К. (1984). Основные проблемы психологической теории эмоций. В кн. В. К. Вилюнас, Ю. Б. Гиппенрейтер (ред.), Психология эмоций. Тексть (с. 3-29). М.: Изд-во Московского университета.

Выготский, Л. С. (1982а). Исторический смысл психологического кризиса. В кн. Л. С. Выготский, Собрание сочинений (т. 1, с. 291-437). М.: Педагогика.

Выготский, Л. С. (1982б). Кризис семи лет. В кн. Л. С. Выготский, Собрание сочинений (т. 4, c. 376-385). М.: Педагогика.

Деева, М. (2010). От индивидуального к разделяемому аффекту: постдюркгеймианская традиция в социологии эмоций. Сочиологическое обозрение, 2, 134-154.

Зорин, А. Л. (2006). Понятие «литературного переживания» и конструкция психологического протонарратива. В кн. Г. В. Обатнин (ред.), История и повествование: Сборник статей (с. 12-27). М.: НЛО.

Карягина, Т. Д. (2016). Эмпатия как метод: точка зрения современной гуманистической психотерапии. Консультативная психология и психотерапия, 5, 178-204. https://doi.org/10.17759/ cpp. 2016240510

Кутковой, Н. А., Стефаненко, Т. Г. (2014). Понятие эмоций в социальной психологии XXI века: основные подходы. Психологические исследования, 7(33), 7. http://psystudy.ru.

Мамардашвили, М. К. (1992). Как я понимаю философию. М.: Прогресс: Культура.

Микаэлян, Л. Л. (2011). Эмоционально-фокусированная супружеская терапия. Теория и практика. Журнал практической психологии и психоанализа, 3. http://psyjournal.ru/articles/emocionalno-fokusirovannaya-supruzheskaya-terapiya-teoriya-i-praktika?ID $=2855 \&$ sphrase_id=131829

Перлз, Ф. (2001). Внутри и вне помойного ведра. М.: Изд-во Института психотерапии.

Пузырей, А. А. (1986). Культурно-историческая теория Л. С. Выготского и современная психология: Уиебное пособие по курсу общей психологии. М.: Изд-во Московского университета.

Роджерс, К. (1994). Взгляд на терапию. Становление человека. М.: Издательская группа «Прогресс».

Роджерс, К., Матюхина, Э. В., Орлов, А. Б., Шевелева, А. Ю. (2001). Клиентоцентрированный/ человекоцентрированный подход в психотерапии. Вопросы психологии, 2, 48-58.

Сельвини Палаццоли, М., Босколо, Л., Чеккин, Дж., Прата, Дж. (2002). Парадокс и контрпарадокс: Новая модель терапии семьи, вовлеченной в Когито-центр.

Степин, В. С. (2009). Классика, неклассика, постнеклассика: критерии различения. В кн. Л. П. Киященко, В. С. Степин (ред.), Постнеклассика: философия, наука, культура (с. 249-295). СПб.: Издательский дом «Міръ».

Стеценко, А. П. (1990). О роли и статусе методологического знания в современной советской психологии. Вестник Московского университета. Серия 14. Психология, 2, 39-50.

Уайт, М. (2010). Карты нарративной практики: Введение в нарративную терапию. М.: Генезис. 
Уилер, Г. (2005). Гештальттерапия постмодерна: за пределами индивидуализма. М.: Смысл.

Фрейд, 3. (1992). По ту сторону принципа удовольствия. М.: Прогресс/Литера.

Фридман, Д., Комбс, Д. (2001). Конструирование иных реальностей. М.: Независимая фирма «ласс».

Хейли, Д., Эриксон, М. (2001). Стратегии семейной терапии. М.: Институт общегуманитарных исследований.

Хломов, Д. Н. (2000). Гештальт-терапия. В кн. А. М. Боковиков (ред.), Основные направления современной психотерапии (с. 343-371). М.: Когито-Центр.

Черников, А. В. (2011). Эмоционально фокусированная терапия супругов. Руководство для психотерапевтов. Журнал практической психологии и психоанализа, 1. http://psyjournal.ru/articles/emocionalno-fokusirovannaya-terapiya-suprugov-rukovodstvo-dlya-psihoterapevtov

Чеснокова, А. Г. (1999). Психология эмоций в концепции Л.С. Выготского. В кн. Материаль Международной конференции студентов и аспирантов по фундаментальным наукам «Ломоносов-1999». https://www.psychology.ru/lomonosov/tesises/hw.htm

Эриксон, М. (1995). Мой голос останется с вами: Обучающие истории Милтона Эриксона. СПб.: Петербург-XXI век.

Будинайте Гражина Леонардовна - доцент, департамент психологии, факультет социальных наук; академический руководитель магистерской программы «Системная семейная психотерапия», Национальный исследовательский университет «Высшая школа экономики»; член правления Общества семейных консультантов и психотерапевтов; практикующий психотерапевт, кандидат психологических наук.

Сфера научных интересов: классическая и постклассическая методология психотерапии, конструктивистские подходы в психотерапии, исследования живых, в том числе социальных, систем, исследование системы психотерапевтического взаимодействия, семья с супружеским разводом.

Контакты: grazhinabudinayte@gmail.com

Геронимус Иван Александрович - системный семейный психотерапевт; член Общества семейных консультантов и терапевтов; преподаватель магистерской программы «Системная семейная терапия», Национальный исследовательский университет «Высшая школа экономики».

Сфера научных интересов: исследование психотерапевтического взаимодействия.

Контакты: ivangeronimus@yandex.ru 


\title{
What Has "Happened" with Emotions in Constructivist Psychotherapy (Using Solution Focused Brief Therapy as Example)?
}

\author{
G.L. Budinayte ${ }^{a}$, I.A. Geronimus ${ }^{a}$ \\ ${ }^{a}$ HSE University, 20 Myasnitskaya Str., Moscow, 101000, Russian Federation
}

\begin{abstract}
Solution-focused brief therapy, just as other constructivist psychotherapeutic approaches, involves no directive work with client emotions. There are no psychotherapeutic techniques for dealing with emotions, either. For this reason, one sometimes discusses the possibility of including interventions aimed directly at the client's emotions in solution-focused brief therapy in addition to interventions aimed at thought and behavior. We believe that such a discussion should not be simply limited to selecting new therapeutic tools and techniques for brief therapy, but should analyze the methodological foundations of this approach. In this article, we analyze the theoretical background of classical therapeutic approaches that call, from an analytical and structuralist standpoint, for special psychotherapeutic work with the client's emotions as important elements of the mind in their own right. We considered here the approaches of psychoanalysis, Gestalt therapy, humanistic psychotherapy and Emotion-focused therapy, which may be called a neoclassical therapeutic approach. We make a survey of theoretical concepts that emerged in the 20th and 21st centuries in philosophy, psychology, sociology and cultural studies and that make us reconsider the traditional approach to emotions in academic psychology and classical psychotherapy. We describe the emergence of the new post-classical approach to working with emotions by considering the examples of cognitive psychotherapy, system psychotherapy and the therapeutic work of M. Erickson. We formulate the basic principles of the construction of psychotherapeutic interaction based on the theoretical assumptions of postclassical rationality and describe their key methodological differences from the classical approach. These assumptions show that special work with emotions is irrelevant to the constructivist approach.
\end{abstract}

Keywords: constructivist psychotherapy approaches, classical psychotherapy approaches, solution focused brief therapy, empathy, ontologization of emotions, second-order construct, preferred history, life story, solution, emotions transformation as transformation of life context.

\section{References}

Bannink, F. P. (2007). Solution-focused brief therapy. Journal of Contemporary Psychotherapy, 37(2), 87-94. https://doi.org/10.1007/s10879-006-9040-y

Barrett, L. F. (2012). Emotions are real. Emotion, 12(3), 413-429. https://doi.org/10.1037/a0027555

Budinayte, G. L. (2005). Orientirovannaya na reshenie kratkosrochnaya terapiya [Solution focused brief therapy]. In A. V. Chernikov (Ed.), Sistemnaya semeinaya psikhoterapiya: klassika i sovremennost' [Family system psychotherapy: classical and contemporary] (pp. 233-270). Moscow: Klass.

Budinayte, G. L. (2006). Osobennosti obucheniya postklassicheskomu metodu psikhologicheskoi pomoshchi sem'e: $v$ sisteme "Orientirovannoi na reshenie kratkosrochnoi terapii" [The specifics of 
teaching post-classical method of psychological help for families in the system of solution focused brief therapy] [PhD dissertation, Institut Razvitiya Doshkol'nogo Obrazovaniya, Moscow, Russian Federation].

Budinaite, G. L., \& Geronimus, I. A. (2016). Ispol'zovanie v rabote na telefone doveriya podkhoda "Orientirovannaya na reshenie kratkosrochnaya psikhoterapiya" [The use of solution focused brief therapy in the work on the helpline]. Moscow: GBOU VPO MGPPU.

Cabanac, M. (2002). What is emotion? Behavioural Processes, 60(2), 69-83. https://doi.org/10.1016/s0376-6357(02)00078-5

Chernikov, A. V. (2011). Emotsional'no fokusirovannaya terapiya suprugov. Rukovodstvo dlya psikhoterapevtov [Emotion focused therapy for couples. Guidelines for psychotherapists]. Zhurnal Prakticheskoi Psikhologii $i$ Psikhoanaliza, 1. http://psyjournal.ru/articles/emocionalnofokusirovannaya-terapiya-suprugov-rukovodstvo-dlya-psihoterapevtov

Chesnokova, A. G. (1999). Psikhologiya emotsii v kontseptsii L.S. Vygotskogo [The psychology of emotions L.S. Vygotsky's theory]. In Proceedings of the Undergraduate and Postgraduate Student International Conference on Fundamental Sciences "Lomonosov-1999". https://www.psychology.ru/lomonosov/tesises/hw.htm (in Russian)

Deeva, M. (2010). Ot individual'nogo k razdelyaemomu affektu: postdyurkgeimianskaya traditsiya v sotsiologii emotsii [From the individual to shared affect: post-Durkheimian tradition in sociology of emotion]. Sotsiologicheskoe Obozrenie, 2, 134-154.

Dolan, Y. M. (1994). Solution-focused therapy with a case of severe abuse. Constructive Therapies, 1 , $276-294$.

Elliott, R., Bohart, A. C., Watson, J. C., \& Greenberg, L. S. (2011). Empathy. In J. C. Norcross (Ed.), Psychotherapy relationship that work: Evidence-based responsiveness. New York, NY: Oxford University Press. http://doi.org/10.1093/acprof:oso/9780199737208.003.0006

Erickson, M. (1995). Moi golos ostanetsya s vami: Obuchayushchie istorii Miltona Eriksona [My voice will stay with you: Teaching stories by Milton Erickson]. Saint Petersburg: Peterburg-XXI vek.

Fox, N. J. (2015). Emotions, affects and the production of social life. The British Journal of Sociology, 66(2), 301-318. https://doi.org/10.1111/1468-4446.12119

Freedman, J., \& Combs, G. (2001). Konstruirovanie inykh real'nostei [Narrative therapy: The social construction of preferred realities]. Moscow: Nezavisimaya firma "Klass". (Original work published 1996)

Freud, S. (1992). Po tu storonu printsipa udovol'stviya [Beyond the pleasure principle]. Moscow: Progress/Litera. (Original work published 1920 in German)

Frijda, N. H., \& Mesquita, B. (1994). The social roles and functions of emotions. In S. Kitayama \& H. R. Markus (Eds.), Emotion and culture: Empirical studies of mutual influence (pp. 51-87). American Psychological Association. https://doi.org/10.1037/10152-002

Geschwind, N., Arntz, A., Bannink, F., \& Peeters, F. (2019). Positive cognitive behavior therapy in the treatment of depression: A randomized order within-subject comparison with traditional cognitive behavior therapy. Behaviour Research and Therapy, 116, 119-130. https://doi.org/10.1016/j.brat.2019.03.005

Goffman, E. (1973). La mise en scene de la vie quotidienne: T. 1. La présentation de soi [The presentation of self in everyday life. Vol. 1. The presentation of self]. Paris: Minuit.

Gonzalez, C. (2017). Recovering process from child sexual abuse during adulthood from an integrative approach to solution-focused therapy: a case study. Journal of Child Sexual Abuse, 26(7), 785-805. https://doi.org/10.1080/10538712.2017.1354954

Greenberg, L. S., \& Johnson, S. M. (1988). Emotionally focused therapy for couples. Guilford Press. 
Greene, G. J., \& Lee, M.-Y. (2015). How to work with clients' strengths in crisis intervention: A solutionfocused approach. In K. R. Yeager \& A. R. Roberts (Eds.), Crisis intervention handbook: Assessment, treatment, and research (pp. 69-98). Oxford University Press.

Haley, J., \& Erickson, M. (2001). Strategii semeinoi terapii [Strategies of family therapy]. Moscow: Institut obshchegumanitarnykh issledovanii.

Harré, R. (2009). Emotions as cognitive-affective-somatic hybrids. Emotion Review, 1(4), 294-301. https://doi.org/10.1177/1754073909338304

Javanmiri, L., Kimiaee, S. A., \& Abadi, B. A. G. H. (2013). The study of solution-focused group counseling in decreasing depression among teenage girls. International Journal of Psychological Studies, 5(1), 105-111.

Johnson, S. M. (2012). The practice of emotionally focused couple therapy: Creating connection. Routledge.

Karyagina, T. D. (2016). Empathy as a method: from the stainpoint of modern humanistic psychotherapy. Konsultationaya Psikhologiya i Psikhoterapiya [Counseling Psychology and Psychotherapy], 24(5), 178-204. https://doi.org/10.17759/cpp.2016240510 (in Russian)

Khlomov, D. N. (2000). Geshtal't-terapiya [Gestalt therapy]. In A. M. Bokovikov (Ed.), Osnovnye napravleniya sovremennoi psikhoterapii [Main approaches in contemporary psychotherapy] (pp. 343-371). Moscow: Kogito-Tsentr.

Kim, J. S., \& Franklin, C. (2015). Understanding emotional change in solution-focused brief therapy: Facilitating positive emotions. Best Practices in Mental Health: An International Journal, 11(1), 25-41.

Kiser, D. J., Piercy, F. P., \& Lipchik, E. (1993). The integration of emotion in solution focused therapy. Journal of Marital and Family Therapy, 19(3), 233-242. https://doi.org/10.1111/j.17520606.1993.tb00984.x

Kutkovoi, N. A., \& Stefanenko, T. G. (2014). The concept of emotion in social psychology of the XXI century: main approaches. Psikhologicheskie Issledovaniya, 7(33), 7. http://psystudy.ru (in Russian)

Lipchik, E. (2002). Beyond technique in solution-focused therapy: Working with emotions and the therapeutic relationship. Guilford Press.

Mamardashvili, M. K. (1992). Kak ya ponimayu filosofiyu [How I understand philosophy]. Moscow: Progress: Kul'tura.

Maqami, R., Bagajan, K. Q., Yousefi, M. M., \& Moradi, S. (2016). The effectiveness of solution focused group therapy on improving depressed mothers of child abuser families. International Journal of Social, Behavioral, Educational, Economic, Business and Industrial Engineering, 10(1), 291-295. https://doi.org/10.5281/zenodo.1338941

Merscham, C. (2000). Restorying trauma with narrative therapy: Using the phantom family. The Family Journal, 8(3), 282-286.

Mikaelyan, L. L. (2011). Emotsional'no-fokusirovannaya supruzheskaya terapiya. Teoriya i praktika [Emotion focused marital therapy]. Zhurnal Prakticheskoi Psikhologii i Psikhoanaliza, 3. http://psyjournal.ru/articles/emocionalno-fokusirovannaya-supruzheskaya-terapiya-teoriya-ipraktika?ID=2855\&sphrase_id $=131829$

Miller, G., \& de Shazer, S. (2000). Emotions in solution focused therapy: A reexamination. Family Process, 39(1), 5-23. https://doi.org/10.1111/j.1545-5300.2000.39103.x

Mommaerts, J. L., Goubert, L., \& Devroey, D. (2012). Empathy beyond the conceptual level: core nonspecific factors of psychotherapy. Perspectives in Biology and Medicine, 55(2), 175-182. https://doi.org/10.1353/pbm.2012.0018 
Neimeyer, R. A. (2010). Reconstructing the continuing bond: A constructivist approach to grief therapy. In J. D. Raskin, S. K. Bridges, \& R. A. Neimeyer (Eds.), Studies in meaning 4: Constructivist perspectives on theory, practice and social justice (pp. 65-92). New York, NY: Pace University Press.

Perls, F. (2001). Vnutri i vne pomoinogo vedra [In and out the garbage pail]. Moscow: Izdatel'stvo Instituta psikhoterapii. (Original work published 1969)

Piercy, F. P., Lipchik, E., \& Kiser, D. (2000). Miller and de Shazer's article on "Emotions in Solution Focused Therapy”. Family Process, 39(1), 25-28. https://doi.org/10.1111/j.1545-5300.2000.39104.x

Puzyrei, A. A. (1986). Kul'turno-istoricheskaya teoriya L. S. Vygotskogo i sovremennaya psikhologiya [Cultural-historical theory by L.S. Vygotsky and contemporary psychology]. Moscow: Moscow University Press.

Rogers, C. (1994). Vzglyad na terapiyu. Stanozlenie cheloveka [On becoming a person: A therapists view of psychotherapy]. Moscow: Izdatel'skaya gruppa "Progress". (Original work published 1961)

Rogers, C., Matyukhina, E. V., Orlov, A. B., \& Sheveleva, A. Yu. (2001). Klientotsentrirovannyi/chelovekotsentrirovannyi podkhod v psikhoterapii [Client-centered / person-centered approach in psychotherapy]. Voprosy Psikhologii, 2, 48-58.

Selvini Palazzoli, M., Boscolo, L., Cecchin, G., \& Prata, G. (2002). Paradoks i kontrparadoks: novaya model' terapii sem'i, vovlechennoi v shizofrenicheskoe vzaimodeistvie [Paradox and counterparadox: A new model in the therapy of the family in schizophrenic transaction]. Moscow: Kogito-Tsentr. (Original work published 1975 in Italian)

Shean, G. D. (2003). Is cognitive therapy consistent with what we know about emotions? The Journal of Psychology, 137(2), 195-208. https://doi.org/10.1080/00223980309600608

Simon, J. K. (2009). Solution focused practice in end-of-life and grief counseling. New York, NY: Springer Publishing Company.

Stepin, V. S. (2009). Klassika, neklassika, postneklassika: kriterii razlicheniya [Classic, non-classic, post-non-classic: distinguishing criteria]. In L. P. Kiyashchenko \& V. S. Stepin (Eds.), Postneklassika: filosofiya, nauka, kul'tura [Post-non-classic: philosophy, science, culture] (pp. 249295). Saint Petersburg: Izdatel'skii dom "Mir".

Stetsenko, A. P. (1990). O roli i statuse metodologicheskogo znaniya v sovremennoi sovetskoi psikhologii [On the role of status of methodological knowledge in contemporary Soviet psychology]. Vestnik Moskovskogo Universiteta. Seriya 14. Psikhologiya, 2, 39-50.

Stetsenko, A. (2016). The transformative mind: Expanding Vygotsky's approach to development and education. Cambridge University Press.

Varga, A. Ya., \& Budinaite, G. L. (2005). Teoreticheskie osnovy sistemnoi semeinoi psikhoterapii [Theoretical foundations of the systemic family psychotherapy]. In A. V. Chernikov (Ed.), Sistemnay a semeinaya psikhoterapiya: klassika i sovremennost' [Family system psychotherapy: classical and contemporary] (pp. 11-60). Moscow: Klass.

Vasilyuk, F. E. (1988). Urovni postroeniya perezhivaniya i metody psikhologicheskoi pomoshchi [The levels of experience construction and the methods of psychological help]. Voprosy Psikhologii, 5, 27-37.

Vasiliuk, F. E. (2007). Semiotics and empathy techniques. Voprosy Psikhologii, 2, 3-14. (in Russian)

Vilyunas, V. K. (1984). Osnovnye problemy psikhologicheskoi teorii emotsii [Main issues of the psychological theory of emotions]. In V. K. Vilyunas \& Yu. B. Gippenreiter (Eds.), Psikhologiya emotsii [The psychology of emotions] (pp. 3-29). Moscow: Moscow University Press.

Vygotsky, L. S. (1982a). Istoricheskii smysl psikhologicheskogo krizisa [The historical meaning of the psychological crisis]. In L. S. Vygotskii, Sobranie sochinenii [Collected works] (Vol. 1, pp. 291-437). Moscow: Pedagogika. 
Vygotsky, L. S. (1982b). Krizis semi let [The crisis of seven years]. In L. S. Vygotskii, Sobranie sochinenii [Collected works] (Vol. 4, pp. 376-385). Moscow: Pedagogika.

Wampold, B. E. (2015). How important are the common factors in psychotherapy? An update. World Psychiatry, 14(3), 270-277. https://doi.org/10.1002/wps.20238

Watzlawick, P., Beavin Bavelas, J., \& Jackson, D. D. (2000). Pragmatika chelovecheskikh kommunikatsii: Izuchenie patternov, patologii i paradoksov vzaimodeistviya [Pragmatics of human communication: a study of interactional patterns, pathologies, and paradoxes]. Moscow: Aprel'-press. (Original work published 1967)

Wheeler, G. (2005). Geshtal'tterapiya postmoderna: za predelami individualizma [Beyond individualism: Toward a new understanding of self, relationship, and experience]. Moscow: Smysl. (Original work published 2000)

White, M. (2010). Karty narrationoi praktiki [Maps of narrative practice]. Moscow: Genezis. (Original work published 2007)

White, M., \& Epston, D. (1990). Narrative means to therapeutic ends. New York, NY: W.W. Norton Company.

Widen, S. C., \& Russell, J. A. (2010). Descriptive and prescriptive definitions of emotion. Emotion Review, 2(4), 377-378. https://doi.org/10.1177/1754073910374667

Zorin, A. L. (2006). Ponyatie "literaturnogo perezhivaniya" i konstruktsiya psikhologicheskogo protonarrativa [The concept of "literary experience" and construction of psychological proto-narrative]. In G. V. Obatnin (Ed.), Istoriya i povestvovanie [History and story-telling] (pp. 12-27). Moscow: NLO.

Grazhina L. Budinayte - Assistant Professor, Department of Psychology, Faculty of Social Science; Head of the master program "Systemic family therapy", HSE University; Member of the Board of Society of Family councellors and psychotherapists, practicing psychotherapist, $\mathrm{PhD}$ in Psychology.

Research Area: classical and postclassical methodology, constructivist approach in psychotherapy, research of living (social) systems, research of psychotherapeutic interactive systems, family with marital divorce.

E-mail: grazhinabudinayte@gmail.com

Ivan A. Geronimus - family system therapist, member of Society of Family councellors and psychotherapists; Lecturer of master program "Family system therapy", HSE University.

Research Area: psychotherapeutic interaction.

E-mail: ivangeronimus@yandex.ru 